\title{
Special section of SoSyM dedicated to 50 years of Petri nets
}

\author{
Robert France - Bernhard Rumpe
}

Received: 26 March 2014 / Revised: 17 October 2014 / Accepted: 19 October 2014 / Published online: 15 November 2014 (C) Springer-Verlag Berlin Heidelberg 2014

Very few concepts of computer science are so closely linked to the names of their creators as Petri nets are to their inventor Carl Adam Petri. More than 50 years ago, in June 1962, he laid the foundation for a modeling technique that has been continuously worked on ever since. With his stable foundation, numerous and broadly applicable concepts and techniques, special cases, generalizations and adaptations, Petri nets are used in a variety of fields inside and outside computer science. Just as finite automata and their numerous variants are the formal basis for many modeling languages for sequential systems, Petri nets are a basic and precise description of essential concepts and phenomena of discrete distributed systems, which implicitly or explicitly influenced many customdesigned modeling languages. Efficient techniques for proving and checking relevant properties of a system model can be transferred from Petri nets to other modeling languages. The same is true for information and results on those properties that cannot be ascertained or require a very high algorithmic effort. Thus, results of Petri net theory are relevant in many areas where the name "Petri" is not explicitly mentioned. Vice versa, new and custom-designed problems are often easier to analyze and solve in the more general context of Petri nets.

This was the impetus for discussing the basic concepts of Petri nets and highlight current fields of successful application in this special section.

In their introductory article "The concepts of Petri nets", Jörg Desel and Wolfgang Reisig show that there is more to

R. France

Colorado State University, Fort Collins, CO, USA

e-mail: france@cs.colostate.edu

B. Rumpe $(\varangle)$

RWTH Aachen University, Aachen, Germany

e-mail: Bernhard.Rumpe@sosym.org the central ideas of Petri nets than just ellipses, rectangles and playing with tokens.

Three articles portray the use of Petri nets in very different areas: Wil van der Aalst shows in his article "Business process management as the 'Killer App' for Petri nets" how Petri nets can be used to model and analyze business processes and in which places concepts of Petri nets have been incorporated into other modeling languages.

Flexible manufacturing systems use sophisticated software to control the flow of material and the use of machinery. In their article "Petri nets for the control of discrete event systems", Alessandro Giua and Carla Seatzu show how the relevant problems of this area can be solved by modeling and analyzing Petri nets.

In the emerging field of computational biology, it is convenient to model biochemical process chains with (extended) Petri nets to make them easier to understand. How this can be done is shown by Ina Koch in her article "Petri nets in systems biology".

These three articles exemplify the wide applicability of Petri nets. However, there are many other fields of application.

A good model provides the people involved with a clear view of the system. Furthermore, a model should be analyzable, that is, it should be possible to algorithmically derive important system properties. Karsten Wolf's article "The Petri net twist in explicit model checking" addresses this issue.

With problems of decidability and complexity, Alain Finkel and Jérôme Leroux show in their article "Recent and simple algorithms for Petri nets" that Petri nets are a source of exciting and nontrivial research questions in the field of conventional theoretical computer science.

Petri spent almost his entire scientific career as head of the Institut für Informationssystemforschung der Gesellschaft 
für Mathematik und Datenverarbeitung ("Institute for information systems research of the association of mathematics and data processing"-today: Fraunhofer-Institut) in Birlinghoven near Bonn, Germany. This is the topic of Einar Smith's historical essay "Petri and how he saw the world".

When we want to collect data, 52 years after Petri's dissertation, we can look back on 34 annual conferences, dedicated almost exclusively to Petri net theory, publications in the five-digit range and almost four million Google-hits for "Petri nets". There is even a "Petri Net World" that provides a lot of information and guidance.
We would like to thank Wolfgang Reisig und Jörg Desel, who have put together this nice special section, which arose from an initial invitation of an expert voice paper. We feel this is a really nice 50 years anniversary section. We would also like to thank the Springer Verlag for enabling us to publish a joint special section in SoSyM as well as in the German journal "Computer Science-Research and Development" dedicated to the German Researcher Carl Adam Petri.

Carl Adam Petri lived from July 12, 1926, until July 2, 2010 . 